\title{
Crystalline silica and risk of lung cancer in the potteries
}

\author{
N M Cherry, G L Burgess, S Turner, J C McDonald
}

\begin{abstract}
Objective-To evaluate crystalline silica as a human carcinogen.

Methods-A cohort of 5115 men, born 1916-45 and employed in the pottery, refractory, and sandstone industries of Stoke-on-Trent was identified from occupations subject to health surveillance by the local Silicosis Medical Board (now the Department of Social Security). Detailed occupational and smoking histories, and records of small parenchymal opacities on periodic radiographs were extracted from medical records. An exposure matrix was derived from some 1400 personal or static dust samples and tested against the presence of small parenchymal opacities in a subcohort of 1080 men employed for at least 10 years, who had started working in the industry before 1960 .
\end{abstract}

Results-Standardised mortality ratios (SMRs) calculated against mortalities for Stoke-on-Trent, with $\mathbf{9 5 \%}$ confidence intervals (95\% CIs), were raised for all causes $(1.15$ (1.05 to 1.26$))$, lung cancer (1.28 (0.99 to 1.62$)$ ) and non-malignant respiratory disease (2.04 (1.55 to 2.65$)$ ). Average concentration and duration of exposure to silica were, taken together, significantly related to the presence of small opacities $(\geqslant 1 / 0)$. In a nested casereferent analysis of 52 cases of lung cancer and 197 matched referents, conditional logistic regression gave a significantly increased odds ratio (OR) for average silica concentration $\left(\mu \mathrm{g} / \mathrm{m}^{3} .100\right)$, after adjustment for smoking, of $1.66(1.14$ to 2.41$)$ but not for duration of exposure nor, in consequence, for cumulative exposure.

Conclusion-The association between risk of lung cancer and quantitative estimates of silica exposure supports the SMR analysis and implies that crystalline silica may well be a human carcinogen.

(Occup Environ Med 1998;55:779-785)

Keywords: lung cancer; silica; potteries

Until recently little thought was given to the possibility that occupational exposure to crystalline silica might be carcinogenic, but largely as the result of a symposium on silica, silicosis, and cancer, held in North Carolina in $1984^{1}$ this view became seriously considered. In 1986, an International Agency for Research on Cancer (IARC) working group reviewed the question and concluded in their overall evaluation that although there was sufficient evidence for the carcinogenicity of crystalline silica in experimental animals, in humans the evidence was limited. ${ }^{2}$ The reasons for the working group's hesitation were essentially twofold: firstly, that the evidently high risk of lung cancer in people with compensated silicosis could be explained by biases associated with case selection and confounding; secondly, that few if any occupational cohort surveys had adequately excluded exposure from other potential carcinogens, taken account of smoking, or provided qualitative or quantitative findings on exposure-response. In the decade that followed, several stronger epidemiological papers were published, sufficient to justify the IARC in convening a second working group in 1996 to review the evidence on crystalline silica yet again. This time the group concluded that there was now sufficient evidence of human carcinogenicity; however, in their overall evaluation the working group noted that carcinogenicity was (a) "not detected in all industrial circumstances" and (b) "may be dependent on inherent characteristics of the crystalline silica or on external factors affecting its biological activity or distribution of its polymorphs".

Because of the dearth of adequate epidemiological data on workers exposed to silica available in 1986, we explored potential opportunities for research in the United Kingdom. Most promising was the existence of employment and other records of men and women in specific trades and processes exposed to dust, who from 1931 to 1984 when the legislation was revoked, were subject to periodic medical surveillance. Preliminary findings on mortality from lung cancer from a follow up of a stratified sample of the current workforce of the British pottery industry, included in a survey in 1970-1, had been published by Winter et al. ${ }^{4}$ Because of difficulty in ensuring a complete follow up these investigators confined their report to the mortality experience of 3669 men $<60$ years of age. In this cohort 60 deaths from lung cancer were observed against 42.8 expected from national rates (standardised morality ratio (SMR) 1.40, $\mathrm{p}=0.007)$ and 45.6 from locally adjusted rates (SMR 1.32, $\mathrm{p}=0.023)$.

The study on which the present report is based was initiated after discussion with the earlier investigators. Our general approach differed in that it followed the more usual procedure of defining the cohort as subjects at the time of first exposure and in terms of date of birth. Whereas the earlier study covered pottery workers in all parts of the United Kingdom, the present cohort was recruited entirely from employees of the numerous pottery companies with workers subject to 
health surveillance at Stoke-on-Trent together with a much smaller number $(<10 \%$ of the total) in refractory or sandstone work. It is likely that the two cohorts had some members in common.

The cohort mortality study of Staffordshire pottery workers described in this paper is one of the very few designed to consider the risk of lung cancer in men exposed to crystalline silica in whom work histories, smoking habits, chest radiograph readings, and previous exposure to other hazardous dusts were all recorded. Also, quantitative exposure estimates, made and tested against radiographic findings, were available for a nested case-referent analysis of exposure-response. Preliminary findings from this investigation have been published, firstly on proportional mortality, ${ }^{5}$ then on SMRs. ${ }^{6}$ These both showed a substantial excess of lung cancer and non-malignant respiratory disease compared with national (United Kingdom) mortality statistics, but this was much less clear when local (Stoke-on-Trent) rates were used. Preliminary results on all aspects of the survey were recently published in abstract form, ${ }^{7-9}$ so that they could be taken into account by the IARC working group in 1996. It is these results which are now fully described.

\section{Materials and methods}

STUDY POPULATIONS

The cohort

From 1931 to 1984 , United Kingdom employers were required to notify the Silicosis Medical Boards and their successors (now the Benefits Agency of the Department of Social Security (DSS)) of any employee who was to work in specified trades and processes exposed to dust.

At the DSS Boarding Centre, Stoke-onTrent, those thus notified had been entered on a card register which is maintained indefinitely. They were then subject to an initial medical examination and further periodic examinations every 2 years. From 1948 this examination included chest radiographs (posterior-anterior) taken when first (or next) seen and every 4 years thereafter. A standard medical record form, which changed over the years, was completed by the physician at each visit and contained the following information:

- Full name, sex, date of birth, and National Insurance Number

- Job or process for which employed

- Duration of any previous work exposed to dust-for example, coal, asbestos, foundries, quarries etc

- Smoking habit

- Classification of chest radiograph on the International Labour Office (ILO) system.

These records were supposedly destroyed, under the regulations, 10 years after last employment and not later than the age of 70 , but in fact these rules were not rigorously applied. The records were also destroyed after 2 years if the Centre was informed of the subject's death; however, no special steps were taken to learn of these deaths. During the course of the study it became apparent that, contrary to policy, some index cards as well as medical records may have been destroyed for deaths known before 1985 (see below). When medical records had been destroyed, duration of employment could not be estimated from the index cards, but there was no indication that the rules had been applied differentially for those with long or short periods of employment.

A cohort of 7064 was defined from the card register for identification and tracing to be all men born between 1916 and 1945 for whom full name and date of birth were given; no minimum period of employment was specified. Men who had worked previously with asbestos or in foundries were then excluded, as were men recorded as having been employed for $>1$ year in coal mining or exposed to other dusts, largely in masonry or from talc in the rubber industry. Men who had been living outside the pottery areas at the time of the first medical examination were also excluded. This was to reduce the number of men examined at the Centre for exposures other than pottery. As a result the cohort used for the present analysis was limited to 5115 . For these men the date of first employment ranged from 1929 to 1992 , but $80 \%$ were known to have been first employed before 1970 .

Pneumoconiosis subcohort

A subcohort of pottery workers was selected from the main mortality cohort to test whether exposure estimates were related to radiographic changes in a reasonable way. To ensure that members of the subcohort had exposure with the potential to produce radiographic evidence of fibrosis it was restricted to men with at least 10 years in the potteries, beginning before 1960. A total of 1080 workers met these criteria.

\section{Nested case-referent study}

Within the 5115 cohort, 88 had a death certificate (see later) with a diagnosis of lung cancer. Records for 32 of these had been destroyed, following the policy already described. Of those whose records were available none was known to have been exposed to asbestos but three further cases were eliminated because their exposure had been to silica in the sandstone or refractory industry where exposure estimates had not been made and one case because the death from lung cancer had been within 10 years of first pottery exposure (in this case 4 years and 9 months before the death).

Each of the remaining 52 cases was matched with three or four referents (depending on availability) on date of birth and date of first exposure making a total of 247 referents. Matching to \pm 3 years was always achieved for date of first exposure but was extended to \pm 4 years of date of birth. Referents were considered ineligible if they were known never to have smoked (no case fell into this category), if they had ever been exposed to asbestos, if their exposure to silica had been entirely outside the pottery industry, or if they had predeceased the case. 
Table 1 Estimated exposures levels * of respirable crystalline silica in pottery processes 1930-92

\begin{tabular}{|c|c|c|c|c|c|c|c|}
\hline Process & $1930-9$ & $1940-9$ & $1950-9$ & $1960-9$ & $1970-9$ & $1980-9$ & $1990-2$ \\
\hline Material preparation & 600 & 370 & 250 & 175 & 100 & 60 & 45 \\
\hline Body preparation & 400 & 300 & 225 & 170 & 115 & 60 & 50 \\
\hline Primary shaping (production) & 400 & 325 & 250 & 175 & 70 & 60 & 50 \\
\hline Primary shaping (non-production) & 200 & 160 & 125 & 90 & 35 & 30 & 25 \\
\hline Secondary shaping & 500 & 425 & 340 & 180 & 40 & 50 & 40 \\
\hline Firing & 800 & 650 & 500 & 220 & 24 & 20 & 20 \\
\hline Glazing & 250 & 200 & 150 & 100 & 80 & 29 & 25 \\
\hline Tiles & 550 & 450 & 370 & 95 & 80 & 60 & 50 \\
\hline Maintenance & 230 & 190 & 150 & 90 & 50 & 40 & 30 \\
\hline Mould making & 150 & 110 & 70 & 40 & 30 & 20 & 15 \\
\hline Pottery support activities & 20 & 16 & 12 & 9 & 3 & 3 & 2 \\
\hline Pottery activity, no job details known & 200 & 160 & 125 & 90 & 35 & 30 & 25 \\
\hline
\end{tabular}

${ }^{\star}$ Reported as daily 8 hour time weighted airborne concentration in $\mu \mathrm{g} / \mathrm{m}^{3}$.

\section{ASCERTAINMENT OF DEATHS AND CAUSE OF} DEATH

Identifying information on the 5115 members of the cohort was given to the DSS with the request that their vital status be established as of 30 June 1992. By matching against the Department's central registry, all but 58 men $(1.1 \%)$ were traced. From this total, 4352 were reported alive and $705(13.9 \%)$ dead. Of these, 234 died before 1985, 470 in 1985 or later, and one at an unknown date.

Information on deaths was then passed to the Office of Population, Censuses, and Surveys (OPCS) so that certified cause as coded at time of death could be obtained from the National Health Service Central Register. The fact and date of death were confirmed and copies of death certificates obtained for 681 $(96.6 \%)$ of the 705 deaths. Of the 681 deaths, 88 were ascribed to lung cancer (international classification of diseases (ICD) 162).

\section{EXPOSURE ESTIMATES}

Extensive records existed for airborne dust concentration in various parts of the industry recorded since the late 1960 s. $^{10}$ Methods designed to collect static (breathing area) samples for particle counting were widely used in the United Kingdom until the 1960s, when a cyclone was introduced to collect personal samples of respirable sized dust followed by analysis of gravimetric silica mass. More than 1000 such personal samples were identified. These measurements of respirable silica dust fell in the range $0-800 \mu \mathrm{g} / \mathrm{m}^{3}$ (mostly between 50 and 200). In earlier years records were sparse, but some 350 samples were from the 1950 s and 1960s. The earlier measurements were dust particle counts from static samplers. All samples, personal or static, were from random surveys carried out within the industry and were not biased towards exceptionally high exposures.

After a review of the issues surrounding the conversion of results from one method to another, it was decided to make use of that suggested by Rice $e t a l^{11}$ for the dusty trades of North Carolina, USA. This method equated 1 million particles per cubic foot to $0.09 \mathrm{mg} / \mathrm{m}^{3}$ of respirable dust. The use of respiratory protective devices might have complicated exposure estimates but this does not seem to have been a practice in this industry. ${ }^{10}$ Job titles were used to indicate similar levels of exposure unless information was available to the con- trary. By this means, the industry was divided into 11 major process groups comprising, in all, 569 job titles. Air sample results were averaged, particle counts converted to gravimetric mass, categorised by job and decade, and then tabulated into a preliminary exposure matrix. Published literature and unpublished reports of dust control measures or changes to the process or work rate were then used to refine the matrix, particularly for the periods where no sample results were available. Judgement was inevitably needed in taking account of engineering changes.

The final version of the matrix is presented in table 1. In general, it depicts an overall trend toward reduction in exposure over the 60 year span, with considerable variations with process and decade.

For members of the pneumoconiosis subcohort and the nested case-referent study full work histories were extracted from clinical records without knowledge of the radiographic readings or cause of death. Duration was measured and maximum, cumulative and average lifetime exposures to crystalline silica were calculated from the matrix. For the pneumoconiosis subcohort the exposures were up to the time of the first positive reading $(\geqslant 1 / 0)$ or, if all radiographs were normal, to the end of employment or to June 1992 if still employed. For the nested case-referent study each exposure measure was calculated to the time of death of the case, and also to points 10 years and 20 years before this death.

\section{MEASUREMENT OF POTENTIAL CONFOUNDERS}

Cigarette smoking had been recorded at each medical examination. For the present study, information was extracted on number of cigarettes smoked a day either at the last medical examination, or if not a smoker at that time, at the last examination at which the number of cigarettes smoked had been recorded.

Date of birth was extracted from the index card.

Work at any time in firing or a post-firing occupation (secondary shaping or glazing) was also recorded; these jobs potentially entailed, particularly within earlier years, exposure to cristobalite or tridymite. These forms of crystalline silica, caused by sustained heating above $1000^{\circ} \mathrm{C}$, have been suspected of being more fibrogenic than quartz. 
Table 2 Person-years analysis: observed and expected deaths 1985-92

\begin{tabular}{|c|c|c|c|c|c|}
\hline \multirow[b]{2}{*}{ Cause (ICD-9) } & \multirow[b]{2}{*}{ Observed } & \multicolumn{2}{|c|}{ Against rates for England and Wales } & \multicolumn{2}{|c|}{ Against rates for Stoke-on-Trent } \\
\hline & & Expected & $\operatorname{SMR}(95 \% C I)$ & Expected & $\operatorname{SMR}(95 \% C I)$ \\
\hline All malignant disease (140-209) & 150 & 104.3 & $1.44(1.22$ to 1.69$)$ & 133.5 & $1.12(0.95$ to 1.32$)$ \\
\hline Lung cancer (162) & 68 & 35.6 & $1.91(1.48$ to 2.42$)$ & 53.1 & $1.28(0.99$ to 1.62$)$ \\
\hline Cancer of digestive organs (150-159) & 40 & 31.8 & $1.26(0.90$ to 1.71$)$ & 41.4 & $0.97(0.69$ to 1.31$)$ \\
\hline Other cancers $(140-149,160-161,163-209)$ & 42 & 36.8 & $1.14(0.82$ to 1.54$)$ & 39.0 & $1.08(0.78$ to 1.46$)$ \\
\hline Non-malignant respiratory disease $(460-519)$ & 57 & 19.9 & $2.87(2.17$ to 3.72$)$ & 27.9 & $2.04(1.55$ to 2.65$)$ \\
\hline Heart disease $(391-429)$ & 171 & 125.8 & $1.36(1.16$ to 1.58$)$ & 175.3 & 0.98 (0.83 to 1.13$)$ \\
\hline Cerebrovascular disease $(430-438)$ & 17 & 18.7 & $0.91(0.53$ to 1.46$)$ & 21.3 & $0.80(0.46$ to 1.28$)$ \\
\hline Accidental injury (800-998) & 9 & 15.6 & $0.58(0.26$ to 1.09$)$ & 13.9 & $0.65(0.29$ to 1.23$)$ \\
\hline All causes & 470 & 321.1 & $1.46(1.33$ to 1.60$)$ & 409.1 & $1.15(1.05$ to 1.26$)$ \\
\hline
\end{tabular}

RADIOGRAPHIC READINGS

The radiographs were taken either at first employment, or, for those employed before 1948 , as soon as practicable after this date and subsequently every 4 years. These were read and recorded by medical officers of the Department of Social Security trained and experienced in the ILO classifications in current use. At least one chest radiograph was available for 4247 workers, $83 \%$ of the cohort. In the present study the date of the first reading on the ILO classification for small parenchymal opacities of $\geqslant 1 / 0$ was recorded together with the reading at this date and at the last available radiograph.

\section{STATISTICAL ANALYSES}

Person-years analysis

Standardised mortality ratios (SMRs) were computed with two sets of rates, those for England and Wales and those for Stoke-on-Trent, standardising for quinquennia of birth and age at death. Because of the possibility that bias might have been introduced in the analysis of early deaths by the inadvertent destruction of index cards for deaths known before 1985, the analysis was limited to mortality to June 1992 in the cohort of 4822 men known to be alive at 1 January 1985. Among these men 470 deaths occurred, 68 from lung cancer.

Analysis of the pneumoconiosis subcohort

The prevalence of radiographic change $(\geqslant 1 / 0)$ was calculated for each measure of exposure. With unconditional logistic regression in an unmatched case-referent design, odds ratios (ORs) were calculated for each exposure measure, with allowance for possible confounding by smoking and potential exposure to cristobalite or tridymite.

Analysis of the nested case-referent study

The relation of exposure to lung cancer was examined in case-referent matched sets by conditional logistic regression analysis, assuming multiplicative relative risks. To assist presentation of the results, cumulative exposure was divided by 1000 , mean concentration by 100 , and duration by 10 before entry in the regression analysis.

\section{Results}

PERSON-YEARS ANALYSIS

The observed to expected ratios based on rates for England and Wales and for Stoke-on-Trent are given in table $2 .{ }^{6}$ Against national rates the ratios were significantly increased for all causes, all malignancies, lung cancer, and nonmalignant respiratory disease. With Stoke-onTrent rates as reference the differences were greatly reduced. However, the SMRs for all causes, for lung cancer, and for non-malignant respiratory disease remained raised; the lower bound for the $95 \%$ confidence interval $(95 \%$ CI) for lung cancer was marginally less than 1.00 but on a $\chi^{2}$ test the observed number of cases differed significantly from expectation $\left(\chi^{2}\right.$ $=3.91 ; \mathrm{p}<0.05)$.

RADIOGRAPHIC CHANGE AND EXPOSURE

In the subcohort of 1080 selected for this analysis, $64(5.9 \%)$ had a least one radiograph read as $\geqslant 1 / 0$ for small opacities on the ILO classification, for the present purpose considered abnormal. Of the 64,21 had a reading $\geqslant$ $2 / 1$. Mean dates of birth, of starting work, and of first abnormal radiograph are shown in table 3. Those with abnormal radiographs were born and started work earlier than those whose radiographs were read as normal $(\leqslant 1 / 0)$. Those whose first radiograph was read as $\geqslant 2 / 1$ had started work earlier than those first identified as having an ILO score of $1(1 / 0,1 / 1$, or $1 / 2$ ) and the opacities were detected after a shorter period of employment.

The prevalence of small opacities increased with cumulative exposure (table 4). Among those who had ever smoked the prevalence was about twice that in non-smokers. A small group of 14 without information on smoking had an unexpectedly high prevalence of abnormal chest radiographs. All but three had missed earlier radiographic screening, and despite a mean duration of exposure of some 19 years, had no history of previous smoking. Eight were found to have abnormal radiographs, seven with an ILO classification of $\geqslant 2 / 1$. Further analyses of the subcohort excluded these 14 workers.

Table 3 Description of the pneumonoconiosis subcohort

\begin{tabular}{|c|c|c|c|c|c|}
\hline & \multicolumn{5}{|c|}{$\begin{array}{l}\text { ILO classification of small parenchymal } \\
\text { opacities }\end{array}$} \\
\hline & 0 & 1 & 2 & Overall & $p$ Value \\
\hline \multicolumn{6}{|c|}{ Date of birth: } \\
\hline Mean & 1933 & 1936 & 1921 & 1933 & \multirow[t]{2}{*}{$<0.001$} \\
\hline SD & 6.3 & 6.6 & 4.5 & 6.2 & \\
\hline \multicolumn{6}{|c|}{ Date of starting: } \\
\hline Mean & 1950 & 1942 & 1936 & 1949 & \multirow[t]{2}{*}{$<0.001$} \\
\hline SD & 6.6 & 7.0 & 2.1 & 6.6 & \\
\hline \multicolumn{6}{|c|}{ Date of radiograph:* } \\
\hline Mean & 1980 & 1976 & 1961 & 1980 & \multirow[t]{3}{*}{$<0.001$} \\
\hline SD & 9.6 & 9.5 & 6.9 & 9.9 & \\
\hline $\mathrm{n}$ & 1016 & 43 & 21 & 1080 & \\
\hline
\end{tabular}

$\star$ First recorded as $\geqslant 1 / 0$. Last if all recorded as normal. 
Table 4 Prevalence of small parenchymal opacities ( $\geqslant 1 / 0$ ) by cumulative exposure and smoking

\begin{tabular}{|c|c|c|c|c|c|c|c|c|}
\hline \multirow[b]{2}{*}{ Exposure $\left(\mu g / m^{3} y\right)$} & \multicolumn{2}{|l|}{ Non-smoker } & \multicolumn{2}{|l|}{ Smoker } & \multicolumn{2}{|c|}{ UK Smoking } & \multicolumn{2}{|l|}{ Overall } \\
\hline & Prevalence & $n$ & Prevalence & $n$ & Prevalence & $n$ & Prevalence & $n$ \\
\hline$<2000$ & 0 & 30 & 0 & 78 & 0 & 1 & 0 & 109 \\
\hline 2000-3999 & 0.9 & 112 & 1.8 & 331 & 33.3 & 6 & 2.0 & 449 \\
\hline $4000-5999$ & 2.9 & 70 & 6.3 & 224 & 100.0 & 3 & 6.4 & 257 \\
\hline$\geqslant 6000$ & 9.3 & 43 & 16.3 & 178 & 75.0 & 4 & 16.0 & 225 \\
\hline Overall & 2.7 & 255 & 6.0 & 811 & 57.1 & 14 & 5.9 & 1080 \\
\hline
\end{tabular}

Odds ratios were calculated separately for cumulative exposure, duration, and average concentration (cumulative exposure and duration) both before and after adjustment for smoking (table 5). Cumulative exposure and average concentration entered as continuous variables were both strongly related to the presence of small opacities. The likelihood ratio statistic associated with mean concentration ( 35.7 on $1 \mathrm{df}$ ) was marginally greater than that for cumulative exposure (34.1 also on 1 df). Duration of exposure was not significantly related to radiographic reading. It did, however, add somewhat to mean concentration when both were in the model (concentration OR 3.10, 95\% CI 2.19 to 4.38; duration OR $1.37,95 \%$ CI 1.05 to 1.80$)$. In all analyses the inclusion of smoking (which was itself associated with the presence of small opacities by an OR of 2.28 (95\% CI 1.02 to 5.10) marginally reduced the size of the exposure effect without changing the conclusions drawn. In this subcohort working in firing and post-firing jobs did not seem to increase the probability of radiographic changes (OR $0.83,95 \%$ CI 0.41 to 1.67$)$.

\section{CASE-REFERENT ANALYSIS}

Matching on date of birth and date of starting work in the pottery industry was very close, with the mean year of birth 1930 and mean year of starting work 1950, for both the 52 cases of lung cancer and the 195 referents. Date of last medical examination in the pottery industry was somewhat earlier for cases (1969) than referents (1972). For cases, the date of the last medical examination was on average 18.4 years before the date of death.

Cases and referents differed in reported cigarette smoking (table 6). No case was recorded as never having smoked and referents were chosen to exclude known non-smokers. Nevertheless, referents had a significantly higher proportion of ex-smokers $(26.2 \%)$ than cases $(9.6 \%)$. Those with unknown history of smoking (12 cases, 42 referents) had short employment in the industry (on average 4.1 years).

Only three cases and 10 referents were known to have had an abnormal radiograph

Table 5 Relation of small parenchymal opacities $(\geqslant 1 / 0)$ to each exposure variable (unconditional logistic regression analysis $(n=1066)$ )

\begin{tabular}{|c|c|c|c|c|}
\hline \multirow[b]{2}{*}{ Exposure index } & \multicolumn{2}{|c|}{ Unadjusted } & \multicolumn{2}{|c|}{$\begin{array}{l}\text { Adjusted for ever or never } \\
\text { smoked }\end{array}$} \\
\hline & $O R$ & $95 \% C I$ & $O R$ & $95 \% C I$ \\
\hline Cumulative/1000 ( $\left.\mu \mathrm{g} / \mathrm{m}^{3} . \mathrm{y}\right)$ & 1.38 & 1.24 to 1.53 & 1.37 & 1.24 to 1.53 \\
\hline Mean concentration $/ 100\left(\mu \mathrm{g} / \mathrm{m}^{3}\right)$ & 2.69 & 1.96 to 3.70 & 2.66 & 1.94 to 3.66 \\
\hline Duration/10 (y) & 1.06 & 0.82 to 1.37 & 1.08 & 0.83 to 1.40 \\
\hline
\end{tabular}

(ILO $\geqslant 1 / 0)$. No radiograph was recorded for eight cases and 25 referents and again the period of employment was short (average 5.1 years).

Odds ratios calculated separately for cumulative exposure, duration, and mean concentration, lagged by 0,10 , and 20 years are shown in table 7 . Only mean concentration of exposure was positively related to lung cancer $(p<0.008$ at all three lag periods). Neither cumulative exposure nor duration was associated with lung cancer in the expected direction; indeed cases had shorter exposure. When duration was added to a model already including mean concentration and smoking, no significant improvement in the model was found $(\mathrm{p}=0.42)$.

Lagging had little effect on risk estimates, as might be expected from the long period between last medical examination (reflecting last employment in exposed jobs) and death. Further analysis was restricted to exposure variables lagged by 10 years.

It was previously reported from this study ${ }^{8}$ that both maximum exposure and exposure to processes containing heated silica were positively related to lung cancer. This was indeed the case (maximum exposure $\geqslant 400 \mathrm{mg} / \mathrm{m}^{3} \mathrm{OR}$ 2.16, $95 \%$ CI 0.98 to 4.74 ; heated silica OR $2.19,95 \%$ CI 1.06 to 4.51$)$. When, as previously, mean concentration was entered as a dichotomous factor, both added to the model. However, in the present detailed analysis, with mean concentration entered as a continuous variable, neither maximum exposure nor exposure to heated silica changed the results to an important extent (maximum exposure $\geqslant 400$ : OR $1.29,95 \%$ CI 0.47 to 3.55; heated silica OR $1.64,95 \%$ CI 0.68 to 3.94), reflecting the close correspondence between heat related jobs and high exposure.

The presence of small opacities was unrelated, in the logistic regression analysis, to lung cancer either alone $(\mathrm{p}=0.78)$ or after adjust-

Table 6 Percentage distribution by smoking and radiographic data for cases and referents

\begin{tabular}{lcc}
\hline & Cases (\%) & Referents (\%) \\
\hline Cigarette smoking: & & \\
Ex-smoker & 9.6 & 26.2 \\
$<10$ & 13.5 & 18.5 \\
$10<20$ & 26.9 & 25.6 \\
$\geqslant 20$ & 26.9 & 13.3 \\
Unknown & 23.1 & 16.4 \\
Total & 100.0 & 100.0 \\
n & 52 & 195 \\
Small opacities: & & \\
No & 78.8 & 82.1 \\
Yes & 5.8 & 5.1 \\
UK & 15.4 & 12.8 \\
Total & 100.0 & 100.0 \\
$\mathrm{n}$ & 52 & 195 \\
\hline
\end{tabular}


Table 7 Relation of lung cancer to each exposure variable (conditional logistic regression analysis)

\begin{tabular}{|c|c|c|c|c|c|c|}
\hline & \multicolumn{2}{|c|}{ No lag } & \multicolumn{2}{|c|}{ Lagged $10 y$} & \multicolumn{2}{|c|}{ Lagged $20 y$} \\
\hline & $O R$ & $95 \% C I$ & $O R$ & $95 \% C I$ & $O R$ & $95 \% C I$ \\
\hline \multicolumn{7}{|l|}{ Cumulative exposure: } \\
\hline Unadjusted & 0.92 & 0.79 to 1.08 & 0.93 & 0.79 to 1.09 & 0.93 & 0.77 to 1.11 \\
\hline Adjusted for smoking & 1.01 & 0.85 to 1.19 & 1.02 & 0.86 to 1.21 & 1.01 & 0.84 to 1.22 \\
\hline \multicolumn{7}{|l|}{ Duration: } \\
\hline Unadjusted & 0.73 & 0.55 to 0.96 & 0.67 & 0.47 to 0.95 & 0.49 & 0.29 to 0.85 \\
\hline Adjusted for smoking & 0.79 & 0.56 to 1.13 & 0.75 & 0.48 to 1.18 & 0.59 & 0.30 to 1.17 \\
\hline \multicolumn{7}{|l|}{ Average concentration: } \\
\hline Unadjusted & 1.70 & 1.18 to 2.44 & 1.67 & 1.18 to 2.35 & 1.57 & 1.12 to 2.20 \\
\hline Adjusted for smoking & 1.67 & 1.13 to 2.47 & 1.66 & 1.14 to 2.41 & 1.60 & 1.11 to 2.31 \\
\hline
\end{tabular}

ment for mean concentration and smoking $(\mathrm{p}=0.68)$.

\section{Discussion}

The findings from this cohort study show that men working in the pottery industry had more deaths than expected from lung cancer and non-malignant respiratory disease compared with the national population, or to a lesser extent, that of Stoke-on-Trent. Moreover, from the nested case-referent analysis, it seems that lung cancer was strongly related to the mean concentration of silica to which men had been exposed even after allowing for smoking and duration of exposure. These findings indicate that exposure to crystalline silica, at least in this industry, carried an increased risk of lung cancer.

The data available to us were unusual in that we had information recorded at regular intervals from first pottery exposure, on smoking, objective readings of periodic chest radiographs, and on previous occupational exposure to other hazardous dusts. Moreover, the work histories were sufficiently detailed for an exposure matrix, derived from about 1400 dust measurements, to be successfully tested for criterion validity ${ }^{12}$ against radiographic scores, before use in the nested case-referent analyses. Finally, the level of tracing by the DSS (99\%) and of death certificate ascertainment by the OPCS (97\%) would be difficult to better. Against all this is the serious possibility of nonrandom removal and destruction of records at the local DSS office. To minimise this possibility several strategies were adopted. Firstly, the cohort for the mortality study was confined to the period since 1984. Next, the analysis of the pneumoconiosis subcohort was repeated ${ }^{12}$ in a reduced cohort in which no record was eligible for destruction, and comparable results were obtained. Finally, for the case-referent study in which all lung cancer deaths with extant records were used, evidence of possible bias was sought with information on the death certificates. For those with extant records pottery work was recorded in $52 \%$; for those whose records were missing this was recorded in $48 \%$. Only three workers with lung cancer, whose records had been destroyed, had mention of silicosis on the death certificate: this did not suggest important bias in destruction.

If exposure to silica in this cohort was indeed related to lung cancer, the lack of any important relation to cumulative exposure, which arises directly from cases having shorter duration of employment, requires further con- sideration. Those who were later to develop lung cancer left the pottery industry, on average aged 39 years, some 3 years before their age matched referents. Given the duration of gap (18 years) between the end of pottery employment and death, and for the most part, absence of small opacities on the last radiograph, ill health (except possibly bronchitic symptoms), is unlikely to have been the explanation.

Examination of the work histories showed that $37 \%$ of cases but only $27 \%$ referents had been employed for $<5$ years in the industry. Durations of employment of 5-15 years were distributed almost equally between cases and referents, but almost half the referents $(49.2 \%)$ and two fifths of the cases $(38.4 \%)$ had worked for longer periods. The mean exposure level, which overall was $21 \%$ higher in cases than referents, was consistently higher at all durations $<20$ years but beyond this there was little difference. Although it seems reasonable to conclude that the increased risk of lung cancer in this cohort was related to the time weighted average level of silica exposure, the effects of duration cannot be assessed.

Our findings must be seen in the context of the other epidemiological evidence considered by the IARC working group in $1996 .{ }^{3}$ Of the many studies reviewed, nine in specific industries were identified as providing the least confounded evidence on the question of silica exposure and cancer risk. The nine included two in refractory brick workers, two (our own and one other) in pottery workers, and one in the diatomaceous earth industry. The remaining four included South Dakota gold miners, Danish stone workers, United States stone workers, and United States granite workers-all four either negative or equivocal. It thus seems that industries associated with heat processes, perhaps because of the associated high exposures, provide the strongest evidence of carcinogenicity and the most promising focus for further research. To be useful future studies must provide both quantitative and qualitative evidence on exposure in relation to risk.

This work was supported in part by a grant from the Department of Social Security, London. The views expressed are not necessarily those of the DSS or any other government department.

1 McDonald JC. Silica, silicosis, and lung cancer. Br F Ind Med 1989;46:289-91.

2 International Agency for Research on Cancer: Monographs on the evaluation of the carcinogenic risk of chemicals to
humans. Silica and some silicates. Vol 42. Lyon: IARC, 1987. 3 International Agency for Research on Cancer: Monographs on the evaluation of the carcinogenic risk of chemicals to 
humans. Silica, some silicates, coal dust and para-aramid fibrils. Vol 68. Lyon: IARC, 1997

4 Winter PD, Gardner MJ, Fletcher AC, et al. Mortality follow-up study of pottery workers: preliminary findings on lung cancer. In: Simonato L, Fletcher AC, Saracci R and Thomas TL, eds. Occupational exposure to silica and cancer risk. Lyon: IARC 1990;83-94. (Scientific Publication No 97.)

5 McDonald JC, Cherry NM, McNamee R, et al. Preliminary analysis of proportional mortality in a cohort of British pottery workers exposed to crystalline silica. Scand $\mathcal{F}$ Work Environ Health 1995;21:63-5.

6 Cherry NM, McNamee R, Burgess GL, et al. Initial findings from a cohort mortality study of British pottery workers. Appl Occup Environ Hyg 1995;10:1042-5.

7 Burgess GL, Turner S, McDonald JC, et al. Cohort mortality study of Staffordshire pottery workers: (I) radiographic validation of an exposure matrix for respirable graphic validation of an exposure matrix for respirab
crystalline silica. Ann Occup Hyg 1997; (suppl):403-7.
8 Cherry NM, Burgess GL, Turner S, et al. Cohort study of Staffordshire pottery workers: (II) nested case-referent analysis of lung cancer. Ann Occup Hyg 1997; (suppl):40811

9 McDonald JC, Burgess GL, Turner S, et al. Cohort study of Staffordshire pottery workers: (III) lung cancer radiographic changes, silica exposure and smoking habit. Ann Occup Hyg 1997; (suppl):412-4.

10 Burgess GL. Development of an exposure matrix for respirable crystalline silica in the British pottery industry. Ann Occup Hyg 1998;42:209-17.

11 Rice CH, Harris RL, Lumsden JC, et al. Reconstruction of silica exposure in the North Carolina dust trades. Am Ind Hyg Assoc f 1984;45:689-96.

12 Burgess GL. Development and application of an exposure matrix for respirable crystalline silica in the British pottery industry, [PhD thesis]. Manchester: University of Manchester 1997.

\section{Correspondence and editorials}

Occupational and Environmental Medicine welcomes correspondence relating to any of the material appearing in the journal. Results from preliminary or small scale studies may also be published in the correspondence column if this seems appropriate. Letters should be not more than 500 words in length and contain a minimum of references. Tables and figures should be kept to an absolute minimum. Letters are accepted on the understanding that they be subject to editorial revision and shortening.

The journal also publishes editorials which are normally specially commissioned. The Editor welcomes suggestions regarding suitable topics; those wishing to submit an editorial, however, should do so only after discussion with the Editor. 